\title{
Participatory mapping and collaborative action for inclusive and sustainable mountain landscape development in Far West Nepal
}

\author{
Prakash Khadka (1), Wei Liu (1), Binod Prasad Parajuli (2), Uttam Pudasaini (3) \\ (1) International Institute for Applied Systems Analysis, Laxenburg, Austria \\ (2) Practical Action Consulting South Asia, Kathmandu, Nepal \\ (3) NAXA Pvt. Ltd., Kathmandu, Nepal \\ Email: khadkaprakash3@gmail.com/khadka@iiasa.ac.at
}

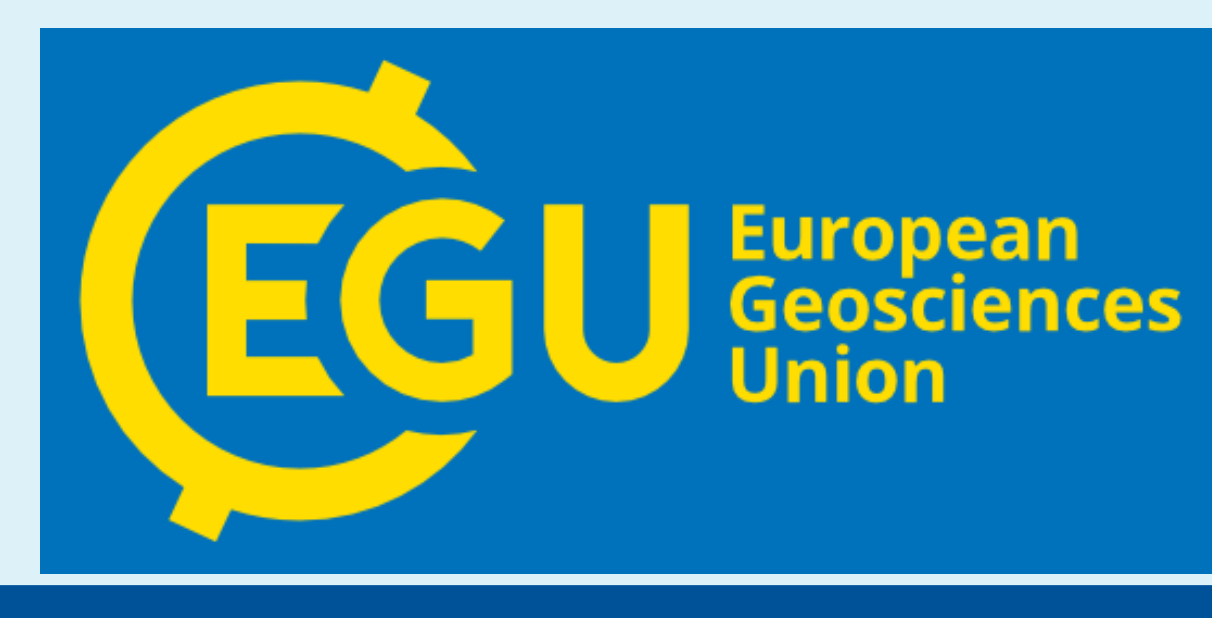

The Problem: Risk information and knowledge deficiency hampers mountain development

$>$ Lack of coordination and collaboration to fulfill the critical knowledge gaps hinder efforts to provide solutions to build sustainable development plans in disaster-prone least developed countries like Nepal.

$>$ Lack of data, especially in terms of spatial information on risk at local levels, seriously compromises efforts for building robust development plans. The collection and generation of such information are generally hindered due to fewer capacities and expertise at local levels where the majority of technical works seek expertise from outside.

$>$ Lack of enabling environment to lower barriers for learning and adopting new tools and approaches to fulfill the problems of data deficiency.
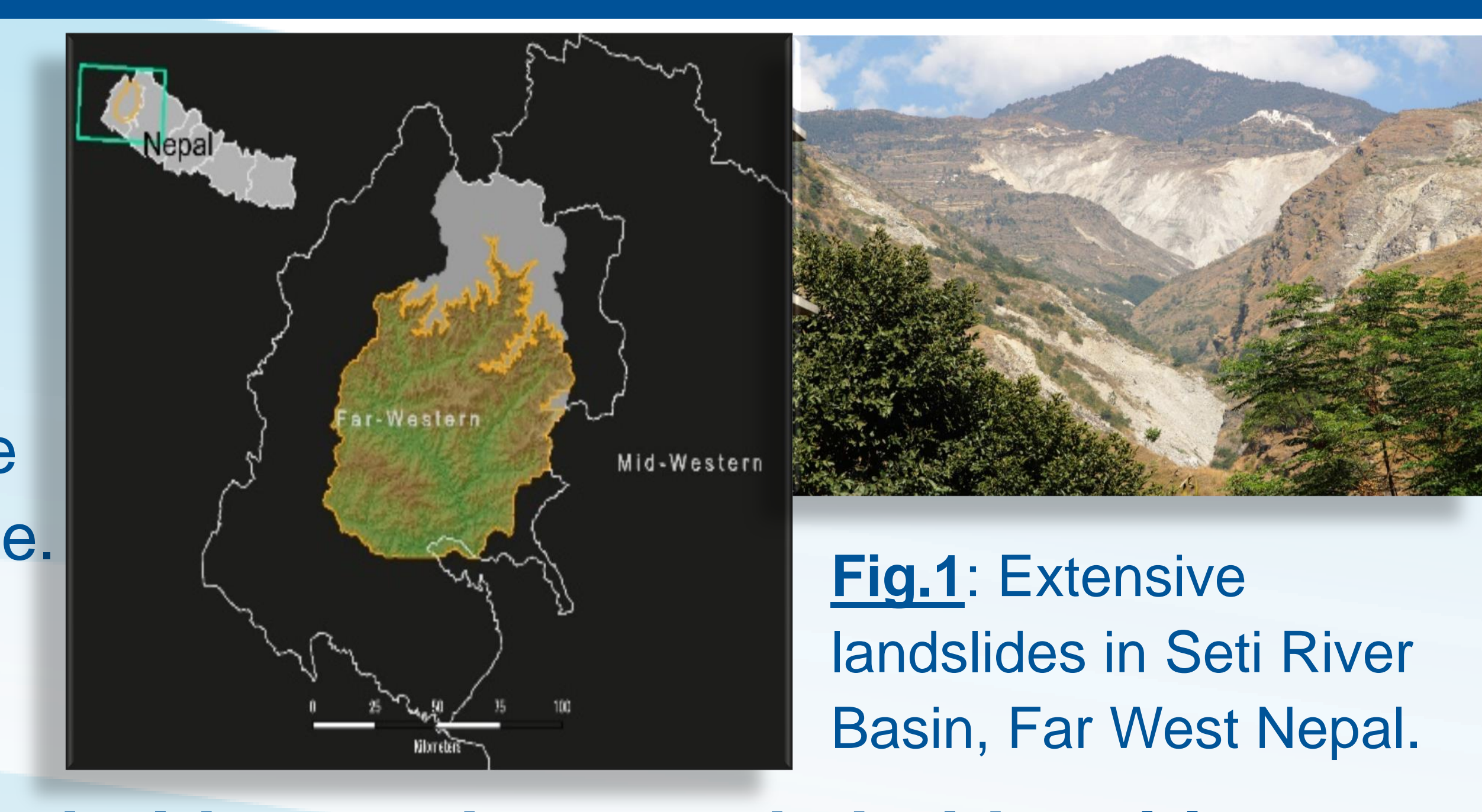

Fig.1: Extensive

landslides in Seti River Basin, Far West Nepal.

Method: An integrated approach of participatory mapping and collaborative action with the stakeholders and non-stakeholder citizens; Tools used: Community Focus Group Discussion (FGDs), Participatory Mapping, Google Earth Imagery, OpenStreetMap (OSM) Remote Mapping, GPS, OSM Tracker, QGIS, and Training, etc.

Steps:

$>$ Consultation meetings with local stakeholders to gauge needs and interests; [Fig. 2(a)]

$>$ Locating the community on the map with hands-on mapping (also, collection of geographic locations); [Fig. 2(b)]

$>$ Conduct remote OSM mapping using satellite images to make preliminary baseline community maps; [Fig. 2(c)]

$>$ Organized FGDs with citizens to discuss and further improve baseline maps with a piece of large print outs of the highresolution aerial photograph from Google Earth or OSM map; [Fig. 2(d)]

$>$ Maintain participatory community mapping activities using baseline maps in situating vulnerability at local scales; [Fig. 2(e)]

$>$ Organize mapathon using the OSM platform, a collaborative effort to map extensively; [Fig. 2(f)]

$>$ Training \& data collection (roads, community facilities, etc.) in the field through practical and easy to use technology; [Fig. 2(g)] $>$ Data validation and upload it to OSM.
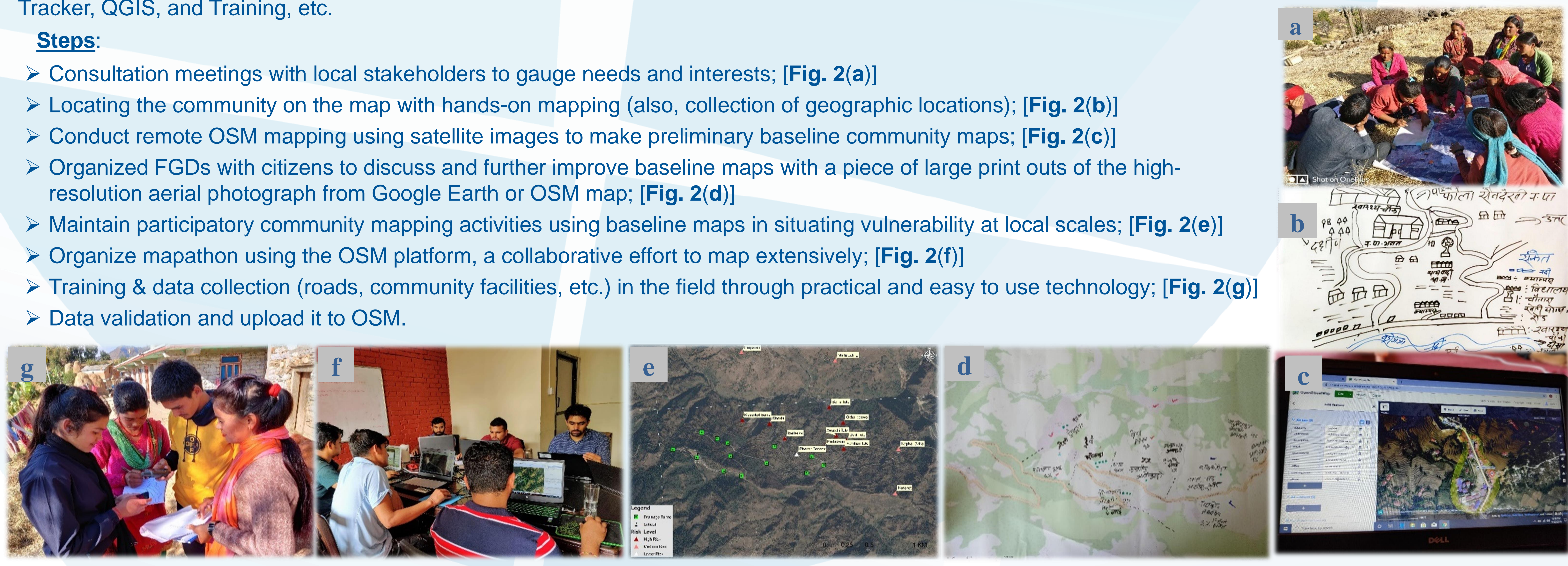

Fig. 2: (a) Community Consultation; (b) Hands-on Mapping; (c) Remote OSM mapping; (d) Improved baseline maps (e) Situating vulnerability at local scales (using Google Earth Imagery); (f) Mapathon: (g) Data collection by local participants'

\section{Preliminary Results: Snapshot}

A
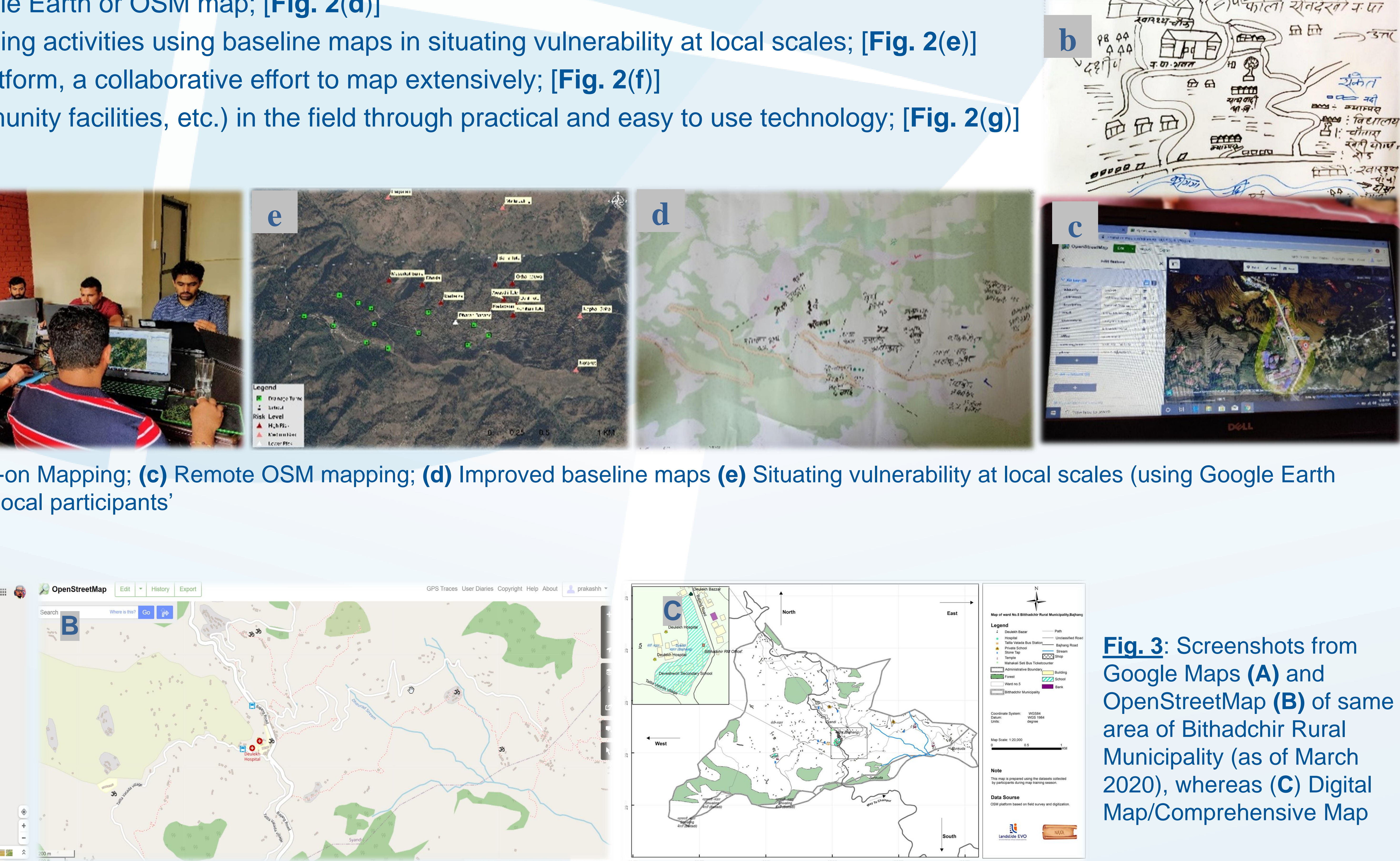

8

$>$ More than 75 percent of houses and constructed units \& $\sim 500 \mathrm{~km}$ of roads mapped in three working municipality.

$>$ "Before this training, none of the ward offices in our municipality were mapped. After going through this training, I was able to map all the ward offices along with the respective contact details and upload the data to OSM platform" - Female IT Officer from Chededaha Rural Municipality.

$>$ "This type of training is very necessary for the engineers of the Municipality who are fully occupied in carrying out various development planning activities (from feasibility study-design/estimation-implementation works) within municipality areas. Spatial knowledge is essential for development planning" - Male Administrative officer from Budhiganga Municipality.

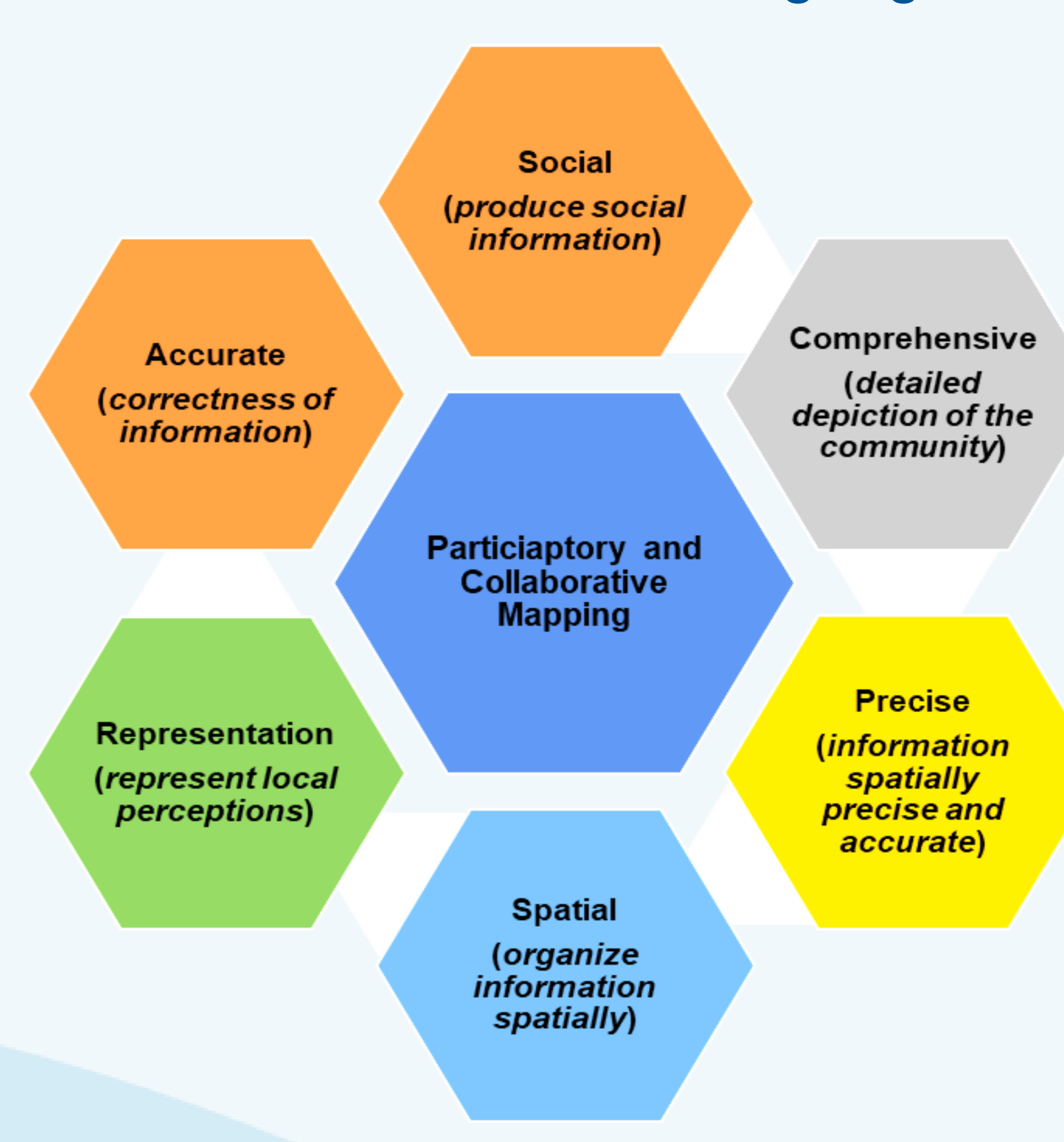

\section{Discussion and Conclusions:}

$>$ Integrated methods like participatory and collaborative mapping are parts of the essential knowledge base to generate spatial information; [Fig.4: shows the dimensions of the integrated method]

$>$ Enhancing inclusiveness to such method comes from both building capacities of local stakeholders, but also lowering barriers for learning and adopting new tools and approaches;

$>$ In this integrated method of mapping involvement of civic tech company, researchers, government, and citizens should engage in producing tools and processes which are user friendly and contextualize;

$>$ The information generated through these integrated methods contributes to evidence-based decision making at local levels under the new federal structure of Nepal;

$>$ Finally, Nepal has its own Disaster Information Management System (DIMS) and these integrated methods will help populate information about landslide risk with less cost and mainstream it into development plans; Limitations and Future Works:

$>$ Digital divide may limit the level of participation from the older generations.

Local government's interest and support are key to its uptake in local land use planning

$>$ Need to integrate into local and national DIMS. 